\title{
Comparative study of patients undergoing check curettage for first trimester incomplete and inevitable abortion under paracervical block versus no anesthesia
}

\author{
Nihita Pandey*, Alka S. Gupta
}

Department of Obstetrics and Gynecology, King Edward Memorial Hospital, Mumbai, Maharashtra, India

Received: 08 February 2016

Accepted: 19 February 2016

*Correspondence:

Dr. Nihita Pandey,

E-mail: kneeheeta@gmail.com

Copyright: ( ) the author(s), publisher and licensee Medip Academy. This is an open-access article distributed under the terms of the Creative Commons Attribution Non-Commercial License, which permits unrestricted non-commercial use, distribution, and reproduction in any medium, provided the original work is properly cited.

\begin{abstract}
Background: The pain experienced during check curettage is due to the dilatation of the cervix, hence it can be hypothesized that in patients with a dilated internal os there should be no need for anesthesia. If it can be proven, then it would prove useful in cases where access to anesthesia is not available, such as primitive hospital set up, while also reducing the cost and complications of anesthesia.

Methods: This study was a prospective randomized single blinded control trial conducted in a tertiary care centre over a period of 15 months with a sample size of 80 patients, 40 in group receiving paracervical block and 40 in group receiving no anesthesia. All patients with spontaneous first trimester incomplete and inevitable abortion were included and randomized in the two groups. Intraoperative vital parameters, vocalization, limb movement and demand for higher anesthesia were noted. Postoperative pain score was obtained based on the numeric rating scale.

Results: The demand for higher anesthesia and satisfaction with procedure was comparable between the two groups $(\mathrm{P}>0.05)$.The average pain score for patients receiving paracervical block was 1.13 and that for patients receiving no anesthesia was $1.79(\mathrm{P}<0.05)$.

Conclusions: The mean pain scores of both the groups were on the lower spectrum of the pain scale with no difference in demand for higher anesthesia. In primary set ups where facilities of anesthesia are not available, curettage can be performed safely without anesthesia, which can prove to be life-saving.
\end{abstract}

Keywords: Curettage, Abortion, Paracervical block

\section{INTRODUCTION}

Check curettage is a commonly done surgical procedure wherein the endometrial walls are curetted to remove the retained products of conception in patients with incomplete and inevitable abortion. Pain perception during the procedure varies among different women depending on the interaction of psychosocial and physical factors. ${ }^{1}$ The Frankenhäuser plexus innervates the cervix and the lower part of the uterine cavity and gets stimulated during cervical dilatation thereby causing pain. ${ }^{1-3}$ Therefore it can be hypothesized that in cases of incomplete and inevitable abortions where the cervical os is already dilated, the need for anesthesia is circumvented, thereby reducing cost of treatment.

Of the various modes of anesthesia that can be given, paracervical block is a form of local anesthesia which serves to block the Frankenhäuser plexus. Different studies advocate different procedure for the paracervical block. $^{4,6}$ While in one study the block is given at cervicovaginal junction at 3 o' clock and 9 o' clock position, the other study uses the position at 4 o' clock and 8 o' clock. It is a safe and effective mode of anesthesia. $^{4-6}$ 
If it can be shown that in an already dilated cervix, the procedure of check curettage can be safely carried out under no anesthesia without causing much morbidity to the patient and then it would prove useful in cases where access to anesthesia is not available. It would also reduce the cost of procedure to the patient. Various complications arising due to anesthesia can be averted. Also, in patients who are bleeding heavily, this procedure can be performed as an outdoor procedure provided proper asepsis is maintained, thereby saving the patient from delay in definitive treatment and further blood loss.

In this study we will try to demonstrate by comparison, the pain experienced during the procedure of check curettage when performed under no anesthesia and under paracervical block.

\section{METHODS}

This study was a prospective randomized single blinded control trial conducted in a tertiary care centre from July 2013 to October 2014. Total 80 patients were selected for the study. Sampling was done using convenience sampling method and the patients were distributed equally into case and control groups using simple random sampling. Patients receiving paracervical block were included in the control group while those receiving no anesthesia were included in study group. All patients above 18 yrs of age admitted in the hospital with first trimester incomplete and inevitable abortion with an open internal cervical os were included in the study irrespective of the associated high risk factors. Those with second trimester abortions and those with a closed internal cervical os were excluded.

A detailed history of the patients, their age and occupation, menstrual and obstetric history was recorded. The chief complaints were noted in chronological order. Patients were explained the numeric rating scale before the procedure. ${ }^{7}$ Single blinding was done; wherein the patients were unaware of the group they were allocated. 40 were distributed into control group wherein they would receive paracervical block at 4 o' clock, 5 o' clock, 7 o'clock and 8 o' clock position at the cevicovaginal junction with $10 \mathrm{ml} 1 \%$ lignocaine at each point. The other 40 were distributed to study group wherein the paracervical injection was given similarly with $10 \mathrm{ml}$ normal saline at each point. Anesthetists were kept standby in case the patients demanded higher anesthesia. The procedure of curettage was started after giving 5 minutes for the action of the block.

Intraoperatively, the pulse and blood pressure was recorded and a note was taken as to whether there was presence of vocalization, limb movement or demand for higher anesthesia during the procedure. These parameters were studied at seven stages of the operation, i.e. at application of the vulsellum, at paracervical injection, at insertion of curette, during curettage of endometrium, at withdrawal of curette, immediately at end of procedure and due to lithotomy position. Pain score for the overall procedure was noted as per the numeric rating scale post operatively. Patients demanding higher anesthesia were excluded from the study and these parameters were not studied in their case. Complications, duration of procedure and overall satisfaction were also noted. The data obtained was compared between the two groups.

\section{RESULTS}

Out of 40 patients in control group, 4 required higher anesthesia whereas out of 40 patients in study group 11 required higher anesthesia.There was no significant difference between the two groups regarding demand for higher anesthesia $(p=0.083)$. The average time taken for the procedure in control group not requiring higher anesthesia was 15 minutes while that in study group not requiring higher anesthesia was 13.79 minutes, which is comparable $(\mathrm{p}>0.05)$. There were no complications and the overall satisfaction was comparable between the two groups $(\mathrm{p}=0.083)$.

Pain score in the study group was significantly more than that of the control group as shown in Table 1.

Table 1: Pain scores in the two groups for patients not requiring higher anesthesia.

\begin{tabular}{|ll|l|}
\hline $\begin{array}{l}\text { Pain Scores } \\
(\text { out of 10) }\end{array}$ & $\begin{array}{l}\text { Control Group } \\
(36)\end{array}$ & $\begin{array}{l}\text { Study Group } \\
(29)\end{array}$ \\
\hline 0 & 6 & 0 \\
\hline 1 & 21 & 11 \\
\hline 2 & 7 & 13 \\
\hline 3 & 2 & 5 \\
\hline Pain Score & $1.13 \pm 0.76^{*}$ & $1.79 \pm 0.72^{*}$ \\
\hline
\end{tabular}

*Mann Whitney test is applied. P: 0.0021

Pain score of the control group is significantly lower as compared to the study group

Intraoperatively, incidence of tachycardia was found to be significantly higher during paracervical injection in the study group (p: 0.01). Incidence of tachycardia was significantly higher in the study group during insertion of curette (p: 0.01) and during curettage of the endometrium (p: 0.02). Incidence of tachycardia was comparable between the two groups at application of vulsellum, withdrawal of curette, immediately at the end of the procedure and due to lithotomy.

Intraoperatively, the incidence of hypertension and vocalization was comparable between the two groups throughout the procedure. The incidence of limb movements was significantly higher in the study group during paracervical injection but was comparable between the two groups during other steps of the procedure. The demand for higher anesthesia was comparable between the two groups at each step of the procedure. 
There were no adverse reactions like vertigo, tinnitus or nausea and vomiting reported due to the paracervical injection. There were no mortalities or intra-operative complications in any of the groups.

\section{DISCUSSION}

We studied various databases and came across three meta-analyses in which multiple studies had been evaluated. ${ }^{1,8,9}$ Each study had investigated the effect of a particular type of anesthesia and compared it to either another type or another dose of anesthesia. In spite of the numerous studies performed, consensus is still lacking as to the preferred and safest mode of anesthesia for patients with an incomplete abortion. Although multiple parameters were compared in these studies, still a lot of parameters were left out, such as that of objective intraoperative analysis. We have tried to cover these details in our study with the aim of establishing the need of anesthesia for patients of incomplete abortion with an open internal os.

Time taken for the procedure was comparable between the two groups with the mean time taken in control group being 15 and that for study group being 13.79. This is possibly because paracervical injection was given in both the groups, hence there was no extra time consumed by the control group for administration of anesthesia.

The pain scores in the study group were significantly higher although the difference in this pain score did not culminate in a demand for higher anesthesia in this group. Intra-operatively, at administration of paracervical block, the incidence of tachycardia was significantly higher in the study group. Since the procedure of administration of paracervical injection was same in both the groups with the difference lying only in the drug administered, it is possible that the cause of tachycardia was anxiety and fear instead of pain. Also, since the injection was given at 4 points, it may be possible that the action of the 1 st injection point started by the time the 4 th point was injected with lignocaine thus reducing incidence of tachycardia in the control group. The incidence of limb movement was higher in the study group at administration of paracervical injection, which cannot be due to pain only and a component of the mental status of the patient needs to be taken into account. A larger and more heterogeneous sample needs to be studied to properly define these unknown variables.

During insertion of the curette, the incidence of tachycardia was significantly higher in the study group as compared to the control group. This can be attributed to lesser pain relief in the study group. But since there was no significant demand for higher anesthesia at this point in any group, it is safe to believe that the pain relief was comparable between the two groups. It is also possible that rather than pain, it was the sensation and awareness of passage of the curette through the os that led to the tachycardia.
During curettage, the incidence of tachycardia was significantly higher in the study group. Here again, there was no significant demand for higher anesthesia at this step in both the groups. Hence, it is safe to presume that the cause for tachycardia was more due to the awareness of the curetting sensation than due to pain. Since the incidence of tachycardia was significantly lower in the control group, it can be stated that paracervical block with lignocaine can block sensations due to intra-uterine manipulations to some extent. More detailed analysis of this phenomenon is required before any definitive statement can be put forth.

In the study by Renner et al the pain during curettage was significantly lower in the chlorprocaine group as compared to bacteriostatic saline. ${ }^{1}$ In the study by Calvache et al, pain during curettage was not studied, but the post operative pain was significantly lower in the lignocaine group as compared to saline. ${ }^{8}$ In the study by Tangsiriwatthana the pain during curettage was significantly lower in the lignocaine group as compared to saline. ${ }^{9}$

\section{CONCLUSIONS}

Judging by the demand for higher anesthesia which was comparable in the two groups, it is safe to conclude that the procedure of check curettage for first trimester incomplete abortions with an open internal os can be performed without any anesthesia without causing any significant pain. Although there was a significant difference in the overall pain scores between the two groups, still the mean pain scores of both the groups were between 1 and 2, which is on the lower spectrum of the pain scale. It can be argued that the patient will remain aware of the uterine intervention if no anesthesia is administered, which can lead to discomfort. But in primary set ups where facilities of anesthesia are not available, the knowledge that the procedure of curettage can be performed safely and without significant pain without anesthesia can prove to be life-saving for the patients.

\section{AKNOWLEDGEMENT}

I would like to express my heartfelt gratitude to my parents, teachers and friends who guided me throughout the study. I would also like to express my gratitude to Dr S. V. Parulekar, head of department of Obstetrics and Gynecology at KEM Hospital for his iron support.

I would like to make a special mention of all my colleagues who helped me at various points in the study, Dr Tejashree Mahadeo, Dr Jyotsna Dwivedi, Dr Amit Patel, Dr Neha saxena, Dr Devendra and Dr Indu Pandey. It has been their undying support that has made my study successful. 
Funding: No funding sources

Conflict of interest: None declared

Ethical approval: The study was approved by the Institutional Ethics Committee

\section{REFERENCES}

1. Renner RM, Jensen JT, Nichols MD, Edelman A. Pain control in first trimester surgical abortion (Review). Cochrane Database of Systematic Reviews. 2009;(2):9.

2. Jurna I. Labor pain-causes, pathways and issues.Schmerz. 1993;7(2):79-84.

3. Rowlands S, Permezel M. Physiology of pain in labour. Baillieres Clin Obstet Gynaecol. 1998;12(3):347-62.

4. Jägerhorn M. Paracervical blocks in obstetrics. An improved injection method. A clinical and radiological study. Acta Obstet Gynecol Scand. 1975;54(1):9-27.

5. Van Praagh IGL, Povey WG. The use of Paracervical Block Anesthesia for Dilatation and Curettage. Canad Med Ass J. 1966;94(6): 267-8.

6. Van Praagh IGL, Povey WG. Paracervical Block Anesthesia for Dilatation and Curettage. Obstet Gynecol. 1967;29(2):167-9.
7. Hawker GA, Mian S, Kendzerska T, French M. Measures of adult pain: Visual Analog Scale for Pain (VAS Pain), Numeric Rating Scale for Pain (NRS Pain), McGill Pain Questionnaire (MPQ), ShortForm McGill Pain Questionnaire (SF-MPQ), Chronic Pain Grade Scale (CPGS), Short Form-36 Bodily Pain Scale (SF-36 BPS), and Measure of Intermittent and Constant Osteoarthritis Pain (ICOAP). Arthritis Care Res. 2011;63:S240-S252.

8. Calvache JA, Delgado-Noguera MF, Lesaffre E, Stolker RJ. Anaesthesia for evacuation of incomplete miscarriage. Cochrane Database Syst Rev. 2012;18:4.

9. Tangsiriwatthana T, Sangkomkamhang US, Lumbiganon P, Laopaiboon M. Paracervical local anaesthesia for cervical dilatation and uterine intervention. Cochrane Database of Systematic Reviews. 2013;9.

Cite this article as: Pandey N, Gupta AS.

Comparative study of patients undergoing check curettage for first trimester incomplete and inevitable abortion under paracervical block versus no anesthesia. Int J Reprod Contracept Obstet Gynecol 2016;5:629-32. 